\section{Gardening Intervention as a Low- to Moderate-Intensity Physical Activity for Improving Blood Lipid Profiles, Blood Pressure, Inflammation, and Oxidative Stress in Women over the Age of 70: A Pilot Study}

\author{
Sin-Ae Park \\ Department of Environmental Health Science, Konkuk University, Seoul \\ 05029, South Korea
}

A-Young Lee

Graduate School of Environmental Science, Konkuk University, Seoul 05029, South Korea

Hee-Geun Park

Sport Science Center in Daejeon, Daejeon 34134, South Korea

\author{
Ki-Cheol Son \\ Department of Environmental Health Science, Konkuk University, Seoul \\ 05029, South Korea; and Graduate School of Environmental Science, \\ Konkuk University, Seoul 05029, South Korea

\section{Dae-Sik Kim ${ }^{1}$ \\ Department of Agricultural and Rural Engineering, Chungnam National University, Daejeon 34134, South Korea}

Wang-Lok Lee ${ }^{1,2}$

Department of Sport Science, Chungnam National University, Daejeon 34134, South Korea

Additional index words. cardiovascular system, elderly women, gardening, horticultural therapy, immunity, human issues in horticulture

\begin{abstract}
The objective of this study was to investigate the effects of a gardening intervention as a physical activity in women aged over 70 years. Twenty-one women aged over 70 years were recruited from the community in Seoul, South Korea. Eleven subjects at a senior community center participated in a 15-session gardening program (twice a week, average 50 minutes per session) from Sept. to Nov. 2015. The rest of the subjects who were recruited from another senior community center acted as the control group. Blood lipid profiles, blood pressure, inflammation in peripheral-blood mononuclear cells (PBMC), and oxidative stress were assessed by a blood test before and after the 15-session gardening intervention. The results showed that the subjects in the gardening intervention as a low- to moderate-physical activity had a significant improvement in their high-density lipoprotein (HDL) level, systolic and diastolic blood pressures, and the variables related to immunity such as tumor necrosis factor- $\alpha$ (TNF- $\alpha$ ) for inflammation in blood and receptor for advanced glycation end products (RAGE) expression for oxidative stress. The results of this study suggested that the 15-session gardening intervention as a low- to moderate-physical activity led to positive effects on the blood lipid profiles, blood pressure, level of inflammatory markers in blood, and oxidative stress of women aged over 70 years.
\end{abstract}

Received for publication 5 Aug. 2016. Accepted for publication 22 Sept. 2016.

This paper was supported by the SMART Research Professor Program of Konkuk University. This work was supported by research fund of Chungnam National University.

${ }^{1}$ These authors contributed equally to this work.

${ }^{2}$ Corresponding author. E-mail: leewl@enu.ac.kr.
Palm et al., 2009; Suzman et al., 2015). Ageing is also associated with multiple systemic dysfunctions of the body, lipid metabolism disorders, and a chronic inflammatory state, which contribute to atherosclerotic cardiovascular disease (Garatachea and Lucia, 2013). Moreover, increased arterial wall stiffness with ageing affects the blood pressure (Izzo et al., 2000).

Regular physical activity has been reported to reduce all-cause mortality (Faselis et al., 2014; Zhao et al., 2015) and increase longevity (Paffenbarger et al., 1993). Furthermore, participation in physical activity intervention in particular has been frequently associated with reduction of many cardiovascular risk factors including blood lipid levels (Taylor et al., 2004), high blood pressure (Mora et al., 2007), obesity (Zmijewski et al., 2015), and type 2 diabetes mellitus (Bacchi et al., 2012), as well as novel risk factors such as inflammation (Mora et al., 2007) and oxidative stress (Schjerve et al., 2008).

Gardening activities are considered lowto moderate-intensity physical activities in the older population (Park et al., 2011, 2012, 2014a). Gardening activities also incorporate the use of various upper and lower limb muscles (Park et al., 2013, 2014b). Reynolds (1999, 2002) reported that gardening improved grip strength, lowered blood pressure, and improved psychological well-being. Park et al. (2009) reported that older gardeners had a stronger grip strength and pinch force, and better self-reported physical health condition when compared with nongardener elderly. Older community gardeners reported less perceived stress when compared with participants of indoor exercise classes (Hawkins et al., 2011). Moreover, gardening is a popular leisure time activity in the elderly (Ashe et al., 2009; Rowinski et al., 2015) and it helps to keep them motivated for continuous participation (Deci and Ryan, 1995; Park et al., 2008). In addition, it has a less risk of injury compared with other types of physical activities (Pons-Villanueva et al., 2010; Powell et al., 1998).

However, there is a lack of research-based findings for applying gardening as a physical activity intervention, as well as regarding its health benefits, especially in relation to blood vasculature and immunity. Therefore, the objectives of this study were to determine the effects of gardening intervention as a lowto moderate-intensity physical activity on the blood vasculature as measured by the blood lipid profile and blood pressure and immunity as measured by inflammation in blood, and oxidative stress in women aged over 70 years.

\section{Materials and Methods}

The elderly population aged over 65 years is the fastest growing group worldwide, exceeding $10 \%$ of the total population in more than 60 countries (Liu and Li, 2015). Ageing is often accompanied by chronic diseases and an increased susceptibility to infections that negatively impact the quality of life of the elderly (Dorshkind et al., 2009;
Subjects. Korean women older than 70 years were recruited from senior community centers. Researchers contacted senior community centers in the same community located in Seoul, South Korea, by phone or through face-to-face meetings with those in charge of these centers to explain the study. Two senior community centers allowed 
researchers to recruit subjects for the study. The researchers visited these centers to explain the purpose and schedule of the study, requirements, and health assessments. Finally, 11 women at $\mathrm{D}$ senior community center and 10 at $\mathrm{H}$ senior community center agreed to participate in this study for the gardening intervention group and the control group, respectively.

During the orientation, subjects gave informed consent. After study completion, subjects were offered $\$ 20$ as an incentive. The study was approved by the Institutional Review Board (7001355-201507-HR-067).

Gardening intervention. A 15-session gardening intervention was developed as a gardenbased low- to moderate-intensity physical activity intervention (Table 1). Participation in low- to moderate-intensity physical activity has been reported to have many health benefits for the elderly, such as improving or maintaining chronic health conditions through its favorable effects on blood lipid profile, blood pressure, and variables related to immunity such as TNF- $\alpha$, monocyte chemoattractant protein-1 (MCP-1), RAGE, NADPHp47, and inducible nitric oxide synthase (iNOS) expression (Brown et al., 2000; Buman et al., 2010; Nelson et al., 2007; Pate et al., 1995; Stefanov et al., 2013; Yu et al., 2009). The intensity of the gardening intervention was determined as low to moderate based on the previous study findings for the exercise intensity of gardening activities in the elderly (Park et al., 2011, 2012, 2014a). Data were collected to determine the perceived and actual exercise intensity of the gardening intervention to establish that the activities selected met the criteria of low to moderate intensity (Table 1).

The 15-session gardening intervention took place during the fall from September to November in Seoul, South Korea. A garden space $(8 \times 5 \mathrm{~m})$ previously prepared in the D senior community center for this study and gardening activities such as planning a garden, making a garden plot, planting, sowing, mulching, fertilizing, watering, weeding, harvesting, garden maintenance, and cleaning the garden plot were performed (Table 1). Seasonal crops such as chives (Allium ascalonicum), chinese cabbage (Brassica campestris ssp. Pekinensis), radish (Raphanus sativus), lettuce (Lactuca sativa), beet (Beta vulgaris), onion (Allium cepa), and spinach (Spinacia oleracea) were grown in the garden.

At the beginning of each session of the gardening intervention, the subjects performed a 5-min warm-up exercise that included stretching exercises for upper and lower bodies by following an instructor. The gardening intervention was run twice weekly with an average of $50 \mathrm{~min}$ per session for a total of 7.5 weeks.

Exercise intensity of the gardening intervention. The exercise intensity of physical activity may be expressed by heart rate (HR), metabolic equivalents (METs) based on oxygen uptake for a specific activity, or by a percentage of maximal HR (\% HR max) (ACSM, 2014). Low-intensity physical activities may be represented by 1.6 to 3.0 METs or $40 \%$ to $55 \%$ HR max; moderate-intensity physical activity by 3.0 to 6.0 METs or $55 \%$ to $70 \%$ HR max; vigorous-intensity physical activity by 6.0 to 9 METs or $70 \%$ to $90 \%$ HR max; and high-intensity physical activity by at least 9.0 METs or at least $90 \%$ HR max (ACSM, 2014).

During the 15-session gardening intervention, four sessions were randomly selected during which the HR was measured to investigate the exercise intensity of the gardening intervention. The 11 subjects in the gardening intervention group wore a HR monitor (OmniSense 3.9.7 Live and Analysis;

Table 1. Heart rate, percentage of maximal heart rate (\% HR max), and rating of perceived exertion (RPE) score for four random sessions of the 15-session gardening intervention in a study for improving health in elderly women by a gardening intervention as a low- to moderate-intensity physical activity.

\begin{tabular}{llccr}
\hline Session & Gardening intervention & Avg $\mathrm{HR}^{\mathrm{z}}$ & $\% \mathrm{HR} \mathrm{max}^{\mathrm{y}}$ & \multicolumn{1}{c}{$\mathrm{RPE}^{\mathrm{x}}$} \\
\hline 1 & Planning garden & - & - & $6.1( \pm 0.2)$ \\
2 & Making garden plots & - & - & $13.3( \pm 1.2)$ \\
3 & Planting transplants & - & - & $11.9( \pm 1.4)$ \\
4 & Making a garden sign & - & - & $11.0( \pm 1.2)$ \\
5 & Hydroponics & - & - & $11.8( \pm 1.3)$ \\
6 & Fertilizing & - & $40.5( \pm 1.5)$ & $12.4( \pm 0.8)$ \\
7 & Making a flower bed & $99.4( \pm 0.9)$ & $71.0( \pm 50.1)$ & $12.6( \pm 1.1)$ \\
8 & Making a vegetable bed & $117.6( \pm 27.1)$ & - & $7.5( \pm 1.5)$ \\
9 & Making organic fertilizers & - & $51.2( \pm 17.6)$ & $11.0( \pm 1.2)$ \\
10 & Mulching & $106.2( \pm 12.1)$ & - & $7.9( \pm 1.7)$ \\
11 & Planting plants & - & - & $11.5( \pm 0.9)$ \\
12 & Harvesting produce & $106.9( \pm 21.7)$ & $55.5( \pm 40.1)$ & $15.2( \pm 0.7)$ \\
13 & Flower arrangement & - & - & $6.0( \pm 0.0)$ \\
14 & Sowing seeds & - & - & $10.4( \pm 1.0)$ \\
15 & Cooking with harvest & $109.4( \pm 20.0)$ & $57.1( \pm 40.7)$ & \\
Average & & & & \\
\hline
\end{tabular}

Results are expressed as mean $\pm \mathrm{SD}$.

${ }^{\mathrm{z}}$ Average HR during four randomly selected gardening intervention sessions was measured.

$\mathrm{y}_{\%} \% \mathrm{HR} \max =[($ target heart rate $-\mathrm{HR}$ rest $) /(\mathrm{HR} \max -\mathrm{HR}$ rest $) \times 100](\mathrm{ACSM}, 2014) ; 40 \%$ to $55 \%$ indicates low intensity, $55 \%$ to $70 \%$ moderate intensity, $70 \%$ to $90 \%$ vigorous intensity, and at least $90 \%$ high intensity (ACSM, 2014).

${ }^{x}$ RPE scale (Borg, 1970). The scale has numerical ratings ranging from 6 to 20. Accordingly, score of 8-10 indicates low-intensity, 11-13 moderate-intensity, 14-16 vigorous-intensity, and above 17 high-intensity physical activity (ACSM, 2014).
Zephyr Technology Corp, Annapolis) on their chest during gardening and the HR data were continuously recorded by a wireless receiver (BioHarness 3; Zephyr Technology Corp, Annapolis). The resting HR of each subject was measured for a $5 \mathrm{~min}$ before starting the testing. To obtain the exercise intensity of the gardening intervention, the HR data were transformed to \% HR max by the formula: [(measured HR - resting HR $) /(\mathrm{HR}$ max resting HR $) \times 100]($ ACSM, 2014).

The rating of perceived exertion scale (RPE) was used to investigate subjective exercise intensity of the gardening intervention (Borg, 1970). This scale was answered by the subjects at the end of each session of the gardening intervention. It is a widely used psychophysical tool to assess subjective perception of effort during exercise (Scherr et al., 2013). This scale ranges from 6 to 20, where 6 means "no exertion at all" and 20 means "maximal exertion" (Borg, 1970). Accordingly, a score of 8-10 indicates lowintensity, 11-13 moderate-intensity, 14-16 vigorous-intensity, and above 17 high-intensity physical activity (ACSM, 2014).

Health assessments. Tests were conducted before and after the 15-session gardening intervention for subjects in both groups to determine the status of the subjects in the four variables of the study. For the health assessments, subjects were required to fast for $9 \mathrm{~h}$ before blood testing.

To analyze blood lipid levels and immunity-related variables such as inflammation in blood and oxidative stress, $10 \mathrm{~mL}$ of blood were collected from the subjects in both groups before and after the intervention. A certified nurse visited the $\mathrm{D}$ and $\mathrm{H}$ senior community centers in the early morning between 7 and 9 AM on separate days to collect the blood samples while the subjects were fasting before breakfast.

To analyze blood lipid levels including those of total cholesterol, HDL cholesterol and low-density lipoprotein (LDL) cholesterol, blood plasma was extracted by centrifugation and then stored in $\mathrm{a}-70^{\circ} \mathrm{C}$ freezer. An automated biochemical analyzer (Fuji 7000i; Fujifilm, Tokyo, Japan) was used to measure the blood lipid levels.

To analyze immunity-related variables such as inflammation in PBMC (MCP-1 and TNF- $\alpha$ ), and oxidative stress (iNOS, NADPH $\mathrm{p} 47$, and RAGE), PBMC were separated from the blood samples using Lymphoprep. Total RNA was then extracted from the separated cells by trizol (Invitrogen, Carlsbad, CA), followed by complementary deoxyribonucleic acid (cDNA) synthesis. Quantitative real-time polymerase chain reaction was conducted using BioRad CFX96 (BioRad, Hercules, $\mathrm{CA})$ to express messenger ribonucleic acid (mRNA) related to blood inflammation and oxidative stress. The analysis was repeated twice for reliability.

Blood pressure of the subjects in the control and gardening intervention groups was measured before and after the 15session intervention. After a 5-min rest on a chair, blood pressure was measured by 
a sphygmomanometer (T4 with Intellisense; Omron Corporation, Tokyo, Japan).

In addition, demographic and health data for both groups was collected and compared with establish that they were comparable groups (Table 2). Body composition parameters such as body weight (kilograms), lean mass (kilograms) and percent fat (\%), and height (centimeter) were measured by a body fat analyzer (IOI 353; Jawon Medical, Gyeongsan, South Korea) and an anthropometer (Ok7979; Samhwa, Seoul, South Korea), respectively. The body mass index (BMI) was calculated as follows: [weight (kilograms)/height ${ }^{2}$ (meters)]. The age-adjusted maximum HR max of the subjects was calculated as follows: $(206-0.88 \times$ age in years $)$ (Sarzynski et al., 2013).

Data analysis. Data such as HR, \% HRmax, and RPE scores were analyzed using Microsoft Excel software (Microsoft Office 2007; Microsoft Corp., Redmond, WA). Chisquare test was used to compare age, height, body composition, resting HR, age-adjusted maximum HR data, education level, marital status, monthly income, and current medication taken by the subjects in both groups. Wilcoxon signed-rank test was used to compare the health assessments, such as blood lipid profiles, blood pressure, inflammation in blood, and oxidative stress, measured before and after the intervention in both groups. Statistical analyses were performed using SPSS software (version 18 for Windows; IBM, Armonk, NY). $P<0.05$ was considered as statistically significant.

\section{Results and Discussion}

Characteristics of subjects. The subjects in the gardening intervention group had a mean age of $80.3 \pm 6.0$ years and were overweight (BMI, $26.7 \pm 4.6 \mathrm{~kg} \cdot \mathrm{m}^{-2}$ ), and those in the control group had a mean age of $81.0 \pm 4.3$ years and were also overweight (BMI, $25.6 \pm 1.9 \mathrm{~kg} \cdot \mathrm{m}^{-2}$ ) (Table 2). No significant difference for all variables was found between the two groups.

Measured and self-reported exercise intensity for participants in the gardening intervention. The 15-session gardening intervention was designed as a low- to moderate-intensity physical activity intervention based on previous study findings (Park et al., 2011, 2012, 2014a). The exercise intensity of gardening intervention was determined using the subjects' HR data that were measured on four random occasions while performing the study intervention. The intensity of gardening intervention in this study had an average of $57.1 \%$ (\% HR max) (Table 1) and was considered as a moderateintensity activity (ACSM, 2014). This result was expected when designing the gardening intervention for this study based on previous findings from the studies concerning exercise intensities of gardening activities (Park et al., 2011, 2012, 2014a). The gardening activities such as digging, raking, weeding, hoeing, and troweling that use both upper and lower body parts were considered as moderate-intensity physical activity in the elderly; whereas gardening activities, such as watering, harvesting, planting transplants, and mixing soil that use only the upper body were considered as low-intensity physical activity in the elderly (Park et al., 2011). Moreover, previous research reported that gardening interventions such as making a vegetable bed or garden maintenance that includes mainly moderate-intensity gardening activities were moderate-intensity interventions (Park et al., 2014a).

Furthermore, the average of self-reported exercise intensity (RPE score) was 10.4, which translates to "very light" as a subjective exercise intensity for the gardening intervention (Table 1). This meant that the perceived exercise intensity was less than the actual intensity. Thus, the gardening intervention in this study was considered as lowto moderate-intensity physical activity.

Physical activity in green environments is associated with health benefits (Coon et al., 2011). Gardening, in particular, provides various health benefits such as reduced total cholesterol, blood pressure, and mortality (Armstrong, 2000; Walsh et al., 2001). In previous studies, elderly gardeners showed significantly more powerful hand strength and pinch force than nongardener elderly (Park et al., 2009). Gardening is expected to increase bone mineral density as a weightbearing exercise (Turner et al., 2002). A longitudinal study showed significant reductions in the risk of heart attacks in 4000 adults older than 60 years through regular activities

Table 2. Demographic and health data of subjects in a study for improving health in elderly women by a 15-session gardening intervention as a low- to moderate-intensity physical activity.

\begin{tabular}{|c|c|c|c|}
\hline Variable & $\begin{array}{c}\text { Gardening } \\
\text { group }(\mathrm{n}=11)\end{array}$ & Control group $(\mathrm{n}=10)$ & $P^{\mathrm{x}}$ \\
\hline Age (year) & $80.3( \pm 6.0)$ & $81.0( \pm 4.3)$ & 0.65 \\
\hline Height $(\mathrm{cm})$ & $148.1( \pm 4.7)$ & $148.6( \pm 4.9)$ & 0.85 \\
\hline \multicolumn{4}{|l|}{ Body composition } \\
\hline Body weight (kg) & $57.8( \pm 8.2)$ & $56.7( \pm 6.0)$ & 0.94 \\
\hline Body mass index $\left(\mathrm{kg} \cdot \mathrm{m}^{-2}\right)^{\mathrm{z}}$ & $26.7( \pm 4.6)$ & $25.6( \pm 1.9)$ & 0.97 \\
\hline Percent fat $(\%)$ & $37.5( \pm 4.4)$ & $38.1( \pm 2.0)$ & 0.54 \\
\hline Lean mass (kg) & $33.1( \pm 2.9)$ & $31.8( \pm 3.2)$ & 0.41 \\
\hline Resting HR (beats/min) & $76.3( \pm 6.5)$ & $72.4( \pm 10.5)$ & 0.36 \\
\hline Age-adjusted maximum HR (beats $/ \min )^{y}$ & $135.4( \pm 5.3)$ & $134.7( \pm 3.8)$ & 0.65 \\
\hline \multicolumn{4}{|l|}{ Education, N (\%) } \\
\hline Elementary school graduate or less & $10(100)$ & $10(100)$ & 1.00 \\
\hline Marital status, N (\%) & & & 1.00 \\
\hline Widowed & $8(80.0)$ & $8(80.0)$ & \\
\hline Married & $2(20.0)$ & $2(20.0)$ & \\
\hline Monthly income, N (\%) & & & 0.31 \\
\hline Less than $\$ 850$ & $10(100)$ & $9(90.0)$ & \\
\hline$\$ 1,700$ to $\$ 2,550$ & $0(0.0)$ & $1(10.0)$ & \\
\hline \multicolumn{4}{|l|}{ Current medications, N (\%) } \\
\hline Blood pressure & $9(81.8)$ & $7(70.0)$ & 0.53 \\
\hline Cholesterol & $3(27.3)$ & $5(50.0)$ & 0.28 \\
\hline Antiarthritic & $0(0.0)$ & $3(30.0)$ & 0.05 \\
\hline Thyroid & $1(9.1)$ & $1(10.0)$ & 0.94 \\
\hline Heart disease & $1(9.1)$ & $0(0.0)$ & 0.33 \\
\hline Blood circulation & $0(0.0)$ & $1(10.0)$ & 0.28 \\
\hline Hip joints & $0(0.0)$ & $1(10.0)$ & 0.28 \\
\hline Osteoporosis & $0(0.0)$ & $1(10.0)$ & 0.28 \\
\hline Backache & $0(0.0)$ & $1(10.0)$ & 0.28 \\
\hline
\end{tabular}

Data are expressed as mean \pm SD unless otherwise specified.

${ }^{\mathrm{z}}$ Body mass index $(\mathrm{BMI})=[$ weight $($ kilograms $)] /[\text { height }(\text { meters })]^{2}$; classification of BMI is as follows $18.5-24=$ normal; $25-29.9=$ overweight; $>30=$ obesity.

${ }^{\mathrm{y}}$ Age-adjusted maximum heart rate $(\mathrm{HR} \max )=206-0.88$ (age in years) (Sarzynski et al., 2013).

${ }^{\mathrm{x}}$ Chi-square test was used to compare demographic data, with $P<0.05$ considered as statistically significant.

Table 3. Effects of gardening intervention on blood lipid profiles in elderly women in a study for improving health by a 15 -session gardening intervention as a low- to moderate-intensity physical activity.

\begin{tabular}{llcc}
\hline & & \multicolumn{1}{c}{ Gardening } \\
Blood lipid profiles (mg/dL) & & group $(\mathrm{n}=11)$ & Control group $(\mathrm{n}=10)$ \\
\hline Total cholesterol & Pretest & $136.5( \pm 35.8)$ & $154.1( \pm 36.1)$ \\
& Posttest & $164.0( \pm 38.8)$ & $158.3( \pm 36.2)$ \\
High-density lipoprotein (HDL) cholesterol & $P^{\mathrm{z}}$ & $0.03^{*}$ & $0.24^{\mathrm{NS}}$ \\
& Pretest & $33.1( \pm 7.9)$ & $37.8( \pm 9.5)$ \\
& Posttest & $40.7( \pm 10.2)$ & $37.7( \pm 11.4)$ \\
Low-density lipoprotein (LDL) cholesterol & Pretest & $0.01^{* *}$ & $0.96^{\mathrm{NS}}$ \\
& Posttest & $90.4( \pm 29.8)$ & $95.3( \pm 30.0)$ \\
& $P$ & $0.06^{\mathrm{NS}}$ & $95.0( \pm 33.9)$ \\
\hline
\end{tabular}

${ }^{\mathrm{z}}$ Values are means $\pm \mathrm{SD}$.

NS, *, ** Nonsignificant or significant at $P<0.05$ or $<0.01$, respectively. 
of daily living such as gardening (EkblomBak et al., 2014).

Blood lipid levels. In regard to the blood lipid levels in this study, the subjects in the 15-session gardening intervention group had significantly increased HDL cholesterol and total cholesterol levels $(P<0.01)$ (Table 3$)$. There was no significant change in HDL cholesterol level in the control group. No significant changes were found in the levels of LDL cholesterol in either group.

The results of this study showed that a 15session gardening intervention may have had a favorable effect on blood lipid levels, and hence may contribute to a decrease the risk of cardiovascular disease. Menopause is often associated with an increase in plasma LDL level, and after the age of 50, females often have higher total cholesterol levels when compared with males of the same age (Kreisberg and Kasim, 1987). Increased physical activity may alter cardiovascular disease risk by favorably altering the plasma lipoprotein profile. Several cross-sectional studies have demonstrated that sedentary individuals (Owens et al., 1990; Wood, 1994) have a higher HDL cholesterol level when compared with sedentary individuals. All these reports indicate that HDL cholesterol can be maintained at high levels with regular physical activity, which is, thus, considered a necessary and important component of coronary heart disease prevention. Therefore, the present study results favored gardening as a physical activity for cardiovascular health promotion.

Blood pressure. Statistically significant differences were observed in systolic and diastolic blood pressures by lowering about $5 \mathrm{~mm} \mathrm{Hg}$ after the gardening intervention (Table 4). There was no change in the control group. This result indicates that the 15session gardening intervention may have had a beneficial effect on blood pressure of elderly women.

Blood pressure (both systolic and diastolic) increases with age (U.S. Department of Health, 1975). Females above the age of 60 have a characteristically higher systolic blood pressure compared with males (Kotchen et al., 1982). In the United States, lowering the average resting blood pressure had a significant impact on reducing mortality from coronary heart disease, stroke, and other causes (Kelley et al., 2001). Regular physical activity reduces blood pressure and is broadly recommended by current American and European hypertension guidelines (Lenfant et al., 2003; Mancia et al., 2007). A meta-analysis showed that regular physical activity reduces the average systolic and diastolic blood pressure by 7 and $5 \mathrm{~mm} \mathrm{Hg}$, respectively (Cornelissen and Fagard, 2005).

Inflammation in blood and oxidant stress. The level of TNF- $\alpha$, which is a proinflammatory cytokine, was significantly lower in the intervention group as compared with the control group (Table 5). The level of MCP1 showed a decrease in the gardening intervention group and the level of MCP-1 showed an increase in the control group although there was no statistically significance (Table 5).

Reduced level of TNF- $\alpha$ plays a protective role against induction of inflammation. On the other hand, increased TNF- $\alpha$ expression caused by obesity or ageing can induce insulin resistance and artery hardening (Hotamisligil et al., 1995). TNF- $\alpha$ level can be reduced by participating in regular physical activities (Pedersen, 2006) and the antiinflammatory action of physical activity can prevent or improve cardiovascular disease and diabetes mellitus. Moderate-intensity aerobic exercise was found to reduce the concentration of TNF- $\alpha$ and interleukin-6 (IL-6) (Kondo et al., 2006; Ziccardi et al., 2002). Kondo et al. (2006) reported that TNF- $\alpha$ level was significantly reduced in obese women by participating in a combined exercise program including walking or jogging for

7 months. Therefore, participation in a regular physical activity restrained the expression of TNF- $\alpha$ (Maeda et al., 2002).

Moreover, RAGE expression in PBMC was significantly decreased in the subjects in the 15-session gardening intervention (Table 6). iNOS and NADPH p47 were also decreased in the intervention group, albeit without statistical significance (Table 6). On the other hand, there was no change in these parameters in the control group.

RAGE, a major mediator for oxidative stress, is expressed in vascular cells, inflammatory cells, peripheral nerves, and heart muscle (Brett et al., 1993) and has a high association with ageing-related diseases such as heart disease, diabetes mellitus, and inflammatory diseases (Abramson et al., 1995). That is, ageing-related diseases can be inferred by measuring the level of RAGE. Moreover, the activation of RAGE induces

Table 4. Effects of gardening intervention on blood pressure in elderly women in a study for improving health by a 15 -session gardening intervention as a low- to moderate-intensity physical activity.

\begin{tabular}{llcc}
\hline Blood pressure $(\mathrm{mm} \mathrm{Hg})$ & & $\begin{array}{c}\text { Gardening } \\
\text { group }(\mathrm{n}=11)\end{array}$ & Control group $(\mathrm{n}=10)$ \\
\hline Systolic blood pressure & Pretest & $148.0( \pm 13.2)$ & $152.7( \pm 19.0)$ \\
& Posttest & $135.5( \pm 11.5)$ & $155.6( \pm 22.7)$ \\
Diastolic blood pressure & $P^{\mathrm{z}}$ & $0.01^{*}$ & $0.06^{\mathrm{NS}}$ \\
& Pretest & $84.6( \pm 10.0)$ & $78.7( \pm 7.5)$ \\
& Posttest & $77.7( \pm 8.4)$ & $78.2( \pm 9.5)$ \\
\hline
\end{tabular}

${ }^{\mathrm{z}}$ Values are means $\pm \mathrm{SD}$

NS, *Nonsignificant or significant at $P<0.05$.

Table 5. Gene expression for proinflammatory proteins in elderly women in a study for improving health by a 15 -session gardening intervention as a low- to moderate-intensity physical activity.

\begin{tabular}{|c|c|c|c|}
\hline $\begin{array}{l}\text { Gene expression for proinflammatory } \\
\text { proteins (ratio to GAPDH) }\end{array}$ & & $\begin{array}{c}\text { Gardening } \\
\text { group }(\mathrm{n}=11)\end{array}$ & $\begin{array}{c}\text { Control } \\
\text { group }(n=10)\end{array}$ \\
\hline \multirow[t]{3}{*}{ Monocyte chemoattractant protein-1 (MCP-1) } & Pretest & $0.88( \pm 0.37)$ & $0.81( \pm 0.34)$ \\
\hline & Posttest & $0.54( \pm 0.45)$ & $1.35( \pm 0.76)$ \\
\hline & $P^{\mathrm{y}}$ & $0.17^{\mathrm{NS}}$ & $0.21^{\mathrm{NS}}$ \\
\hline \multirow[t]{3}{*}{ Tumor necrosis factor- $\alpha$ (TNF- $\alpha)$} & Pretest & $0.74( \pm 0.16)$ & $1.23( \pm 0.65)$ \\
\hline & Posttest & $0.47( \pm 0.24)$ & $1.41( \pm 0.63)$ \\
\hline & $P$ & $0.03 *$ & $0.58^{\mathrm{NS}}$ \\
\hline
\end{tabular}

${ }^{\mathrm{z}}$ Glyceraldehyde 3-phosphate dehydrogenase (GAPDH) that is one of the primers used for real-time quantitative polymerase chain reaction (RT-qPCR) measuring messenger ribonucleic acid (mRNA) related to mediators of inflammation blood.

${ }^{y}$ Values are means \pm SD.

NS, *Nonsignificant or significant at $P<0.05$.

Table 6. Gene expression for oxidant proteins in elderly women in a study for improving health by a 15 -session gardening intervention as a low- to moderate-intensity physical activity.

\begin{tabular}{llll}
\hline Gene expression for oxidant proteins (ratio to GAPDH) & & \multicolumn{1}{c}{$\begin{array}{c}\text { Gardening } \\
\text { group }(\mathrm{n}=11)\end{array}$} & $\begin{array}{c}\text { Control } \\
\text { group }(\mathrm{n}=10)\end{array}$ \\
\hline Inducible nitric oxide synthase (iNOS) & Pretest & $0.68( \pm 0.43)$ & $1.26( \pm 0.75)$ \\
& Posttest & $0.39( \pm 0.34)$ & $1.26( \pm 0.76)$ \\
Receptor for advanced glycation end products (RAGE) & $P^{\mathrm{y}}$ & $0.13^{\mathrm{NS}}$ & $1.00^{\mathrm{NS}}$ \\
& Pretest & $0.78( \pm 0.39)$ & $0.86( \pm 0.31)$ \\
& Posttest & $0.28( \pm 0.23)$ & $1.18( \pm 0.70)$ \\
NADPH oxidase p47 & P & $0.02^{*}$ & $0.58^{\mathrm{NS}}$ \\
& Pretest & $0.28( \pm 0.27)$ & $0.18( \pm 0.11)$ \\
& Posttest & $0.19( \pm 0.08)$ & $0.23( \pm 0.27)$ \\
\hline
\end{tabular}

${ }^{\mathrm{z}}$ Glyceraldehyde 3-phosphate dehydrogenase (GAPDH) that is one of the primers used for real-time quantitative polymerase chain reaction (RT-qPCR) measuring messenger ribonucleic acid (mRNA) related to mediators of oxidant stress.

${ }^{\mathrm{y}}$ Values are means \pm SD.

NS, *Nonsignificant or significant at $P<0.05$. 
TNF- $\alpha$, IL- 6 , and C-reactive protein, which are related to inflammation. The results of this study showed the beneficial effects of the 15-session gardening intervention on the oxidative stress level. Thus, these study results showed that the 15-session gardening intervention may have had a beneficial effect on the assayed markers of immunity as compared with the control group and merit further study.

In conclusion, the 15-session gardening intervention as a low- to moderate-intensity physical activity may have improved HDL cholesterol, blood pressure, and markers of immune activation, such as TNF- $\alpha$ and RAGE expression. These study results show the potential of gardening as a physical activity for improving health in elderly women. Future studies need to have a longer duration and a larger sample size to analyze the effect of a long-term gardening intervention on maintaining or improving health conditions of the elderly.

\section{Literature Cited}

Abramson, M.J., R.M. Puy, and J.M. Weiner. 1995. Is allergen immunotherapy effective in asthma? A meta-analysis of randomized controlled trials. Amer. J. Respir. Crit. Care Med. 151:969974.

American College of Sports Medicine. 2014. ACSM's guidelines for exercise testing and prescription. Lippincott Williams Wilkins, Philadelphia, PA.

Armstrong, D. 2000. A survey of community gardens in upstate New York: Implications for health promotion and community development. Health Place 6:319-327.

Ashe, M.C., W.C. Miller, J.J. Eng, and L. Noreau. 2009. Older adults, chronic disease and leisuretime physical activity. Gerontology 55:64-72.

Bacchi, E., C. Negri, M.E. Zanolin, C. Milanese, N. Faccioli, M. Trombetta, G. Zoppini, A. Cevese, R.C. Bonadonna, F. Schena, E. Bonora, M. Lanza, and E. Bonora. 2012. Metabolic effects of aerobic training and resistance training in type 2 diabetic subjects a randomized controlled trial (the RAED2 study). Diabetes Care 35:676-682.

Borg, G. 1970. Perceived exertion as an indicator of somatic stress. Scand. J. Rehabil. Med. 2:9298.

Brett, J., A.M. Schmidt, Y.S. Zou, S.D. Yan, E. Weidman, D. Pinsky, and D.M. Stern. 1993. Tissue distribution of the receptor for advanced glycation endproducts (RAGE): Expression in smooth muscle, cardiac myocytes, and neural tissue in addition to the vasculature. Amer. J. Pathol. 143:1699-1712.

Brown, M., D.R. Sinacore, A.A. Ehsani, E.F. Binder, J.O. Holloszy, and W.M. Kohrt. 2000. Low-intensity exercise as a modifier of physical frailty in older adults. Arch. Phys. Med. Rehabil. 81:960-965.

Buman, M.P., E.B. Hekler, W.L. Haskell, L. Pruitt, T.L. Conway, K.L. Cain, J.F. Sallis, B.E. Saelens, L.D. Frank, and A.C. King. 2010. Objective light-intensity physical activity associations with rated health in older adults. Amer. J. Epidemiol. 172:1155-1165.

Coon, J.T., K. Boddy, K. Stein, R. Whear, J. Barton, and M.H. Depledge. 2011. Does participating in physical activity in outdoor natural environments have a greater effect on physical and mental wellbeing than physical activity indoors? Systematic review. Environ. Sci. Technol. 45:1761-1772.

Cornelissen, V.A. and R.H. Fagard. 2005. Effects of endurance training on blood pressure, blood pressure-regulating mechanisms, and cardiovascular risk factors. Hypertension 46:667675.

Deci, E.L. and R.M. Ryan. 1995. Efficacy, agency, and self-esteem. Plenum Press, New York, NY.

Dorshkind, K., E. Montecino-Rodriguez, and R.A. Signer. 2009. The ageing immune system: Is it ever too old to become young again? Nat. Rev. Immunol. 9:57-62.

Ekblom-Bak, E., B. Ekblom, M. Vikström, U. de Faire, and M.L. Hellénius. 2014. The importance of non-exercise physical activity for cardiovascular health and longevity. Brit. J. Sports Med. 48:233-238.

Faselis, C., M. Doumas, A. Pittaras, P. Narayan, J. Myers, A. Tsimploulis, and P. Kokkinos. 2014. Exercise capacity and all-cause mortality in male veterans with hypertension aged $\geq 70$ years. Hypertension 64:30-35.

Garatachea, N. and A. Lucia. 2013. Genes, physical fitness and ageing. Ageing Res. Rev. 12:90102.

Hawkins, J.L., K.J. Thirlaway, K. Backx, and D.A. Clayton. 2011. Allotment gardening and other leisure activities for stress reduction and healthy aging. Hort Technology 21:577-585.

Hotamisligil, G.S., P. Arner, J.F. Caro, R.L. Atkinson, and B.M. Spiegelman. 1995. Increased adipose tissue expression of tumor necrosis factor-alpha in human obesity and insulin resistance. J. Clin. Invest. 95:2409-2415.

Izzo, J.L., D. Levy, and H.R. Black. 2000. Importance of systolic blood pressure in older Americans. Hypertension 35:1021-1024.

Kelley, G.A., K.S. Kelley, and Z.V. Tran. 2001. Walking and resting blood pressure in adults: A meta-analysis. Prev. Med. 33:120-127.

Kondo, T., I. Kobayashi, and M. Murakami. 2006. Effect of exercise on circulating adipokine levels in obese young women. Endocr. J. 53:189-195.

Kotchen, J.M., H.E. McKean, and T.A. Kotchen. 1982. Blood pressure trends with aging. Hypertension 4:III128-III134.

Kreisberg, R.A. and S. Kasim. 1987. Cholesterol metabolism and aging. Amer. J. Med. 82:5460.

Lenfant, C., A.V. Chobanian, D.W. Jones, and E.J. Roccella. 2003. Seventh report of the Joint National committee on the prevention, detection, evaluation, and treatment of high blood pressure (JNC 7): Resetting the hypertension sails. Hypertension 41:1178-1179.

Liu, H.H. and J.J. Li. 2015. Aging and dyslipidemia: A review of potential mechanisms. Ageing Res. Rev. 19:43-52.

Maeda, N., I. Shimomura, K. Kishida, H. Nishizawa, M. Matsuda, H. Nagaretani, N. Furuyama, H. Kondo, M. Takahashi, Y. Arita, R. Komuro, N. Ouchi, S. Kihara, Y. Tochino, K. Okutomi, M. Horie, S. Takeda, T. Aoyama, T. Funahashi, and Y. Matsuzawa. 2002. Diet-induced insulin resistance in mice lacking adiponectin. Nat. Med. 8:731-737.

Mancia, G., G. De Backer, A. Dominiczak, R. Cifkova, R. Fagard, G. Germano, G. Grassi, A.M. Heagerty, S.E. Kjeldsen, S. Laurent, K. Narkiewicz, L. Ruilope, A. Rynkiewicz, R.E. Schmieder, H.A.J. Struijker Boudier, and A. Zanchetti. 2007. 2007 Guidelines for the management of arterial hypertension. European Heart J. 28:1462-1536.

Mora, S., N. Cook, J.E. Buring, P.M. Ridker, and I.M. Lee. 2007. Physical activity and reduced risk of cardiovascular events potential mediating mechanisms. Circulation 116:2110-2118.

Nelson, M.E., W.J. Rejeski, S.N. Blair, P.W. Duncan, J.O. Judge, A.C. King, C.A. Macera, and C. Castaneda-Sceppa. 2007. Physical activity and public health in older adults: Recommendation from the American College of Sports Medicine and the American Heart Association. Circulation 116:1094-1105.

Owens, J.F., K.A. Matthews, R.R. Wing, and L.H. Kuller. 1990. Physical activity and cardiovascular risk: A cross-sectional study of middleaged premenopausal women. Prev. Med. 19: 147-157.

Paffenbarger, R.S., Jr., R.T. Hyde, A.L. Wing, I.M. Lee, D.L. Jung, and J.B. Kampert. 1993. The association of changes in physical-activity level and other lifestyle characteristics with mortality among men. N. Engl. J. Med. 328: 538-545.

Palm, H.G., J. Stroble, G. Achatz, F. Von Luebken, and B. Friemert. 2009. The role and interaction of visual and auditory afferents in postural stability. Gait Posture 30:328-333.

Park, S.A., A.Y. Lee, J.J. Kim, K.S. Lee, J.M. So, and K.C. Son. 2014b. Electromyographic analysis of upper and lower limbs muscles during gardening tasks. Korean J. Hort. Sci. Technol. 32:710-720.

Park, S.A., C.A. Shoemaker, and M.D. Haub. 2008. Can older gardeners meet the physical activity recommendation through gardening? HortTechnology 18:639-643.

Park, S.A., C.A. Shoemaker, and M.D. Haub. 2009. Physical and psychological health conditions of older adults classified as gardeners or nongardeners. HortScience 44:206-210.

Park, S.A., J.Y. Lee, K.S. Lee, and K.C. Son. 2014a. Metabolic costs of daily activities in community dwelling older adults. Intl. J. Gerontol. 8:228-229.

Park, S.A., K.S. Lee, and K.C. Son. 2011. Determining exercise intensities of gardening tasks as a physical activity using metabolic equivalents in older adults. HortScience 46:1706-1710.

Park, S.A., K.S. Lee, K.C. Son, and C.A. Shoemaker. 2012. Metabolic cost of horticulture activities in older adults. J. Jpn. Soc. Hort. Sci. 81:295299.

Park, S.A., S.R. Oh, K.S. Lee, and K.C. Son. 2013. Electromyographic analysis of upper limb and hand muscles during horticultural activity motions. HortTechnology 23:51-56.

Pate, R.R., M. Pratt, S.N. Blair, W.L. Haskell, C.A. Macera, C. Bouchard, D. Buchner, W. Ettinger, G.W. Health, A. King, A. Kriska, A.S. Leon, B.H. Marcus, J. Morris, R.S. Paffenbarger, K. Patrick, M.L. Pollock, J.M. Rippe, J. Sallis, and J.H. Wilmore. 1995. A recommendation from the Centers for Disease Control and Prevention and the American College of Sports Medicine. J. Amer. Medical Assn. 273:402-407.

Pedersen, B.K. 2006. The anti-inflammatory effect of exercise: Its role in diabetes and cardiovascular disease control. Essays Biochem. 42:105117.

Pons-Villanueva, J., M. Seguí-Gómez, and M.A. Martínez-González. 2010. Risk of injury according to participation in specific physical activities: A 6-year follow-up of 14356 participants of the SUN cohort. Intl. J. Epidemiology Community Health 39:580-587.

Powell, K.E., G.W. Heath, M.J. Kresnow, J.J. Sacks, and C.M. Branche. 1998. Injury rates from walking, gardening, weightlifting, outdoor bicycling, and aerobics. Med. Sci. Sports Exerc. 30:1246-1249. 
Reynolds, V. 1999. The green gym: An evaluation of a pilot project in Sonning Common, Oxfordshire. Oxford Brookes Univ., Oxford, UK.

Reynolds, V. 2002. Well-being comes naturally: An evaluation of BTCV Green Gym at Portslade, East Sussex. Oxford Brookes Univ., Oxford, UK.

Rowinski, R., A. Dabrowski, and T. Kostka. 2015. Gardening as the dominant leisure time physical activity (LTPA) of older adults from a post-communist country: The results of the population-based PolSenior Project from Poland. Arch. Gerontol. Geriatr. 60:486-491.

Sarzynski, M.A., T. Rankinen, C.P. Earnest, A.S. Leon, D.C. Rao, J.S. Skinner, and C. Bouchard. 2013. Measured maximal heart rates compared to commonly used age-based prediction equations in the heritage family study. Amer. J. Hum. Biol. 25:695-701.

Scherr, J., B. Wolfarth, J.W. Christle, A. Pressler, S. Wagenpfeil, and M. Halle. 2013. Associations between Borg's rating of perceived exertion and physiological measures of exercise intensity. Eur. J. Appl. Physiol. 113:147-155.

Schjerve, I.E., G.A. Tyldum, A.E. Tjønna, T. Stølen, J.P. Loennechen, H.E. Hansen, P.M. Haram, G. Heinrich, A. Bye, S.M. Najjar, G.L. Smith, S.A. Slørdahl, O.J. Kemi, and G.L. Smith. 2008. Both aerobic endurance and strength training programmes improve cardiovascular health in obese adults. Clin. Sci. 115:283-293.
Stefanov, T., A. Vekova, I. Bonova, S. Tzvetkov, D. Kurktschiev, M. Blüher, and T. TemelkovaKurktschiev. 2013. Effects of supervised vs non-supervised combined aerobic and resistance exercise programme on cardiometabolic risk factors. Cent. Eur. J. Public Health 21:8-16.

Suzman, R., J.R. Beard, T. Boerma, and S. Chatterji. 2015. Health in an ageing world: What do we know? Lancet 385(9967):484-486.

Taylor, R.S., A. Brown, S. Ebrahim, J. Jolliffe, H. Noorani, K. Rees, B. Skidmore, J.A. Stone, D.R. Thompson, and N. Oldridge. 2004. Exercise-based rehabilitation for patients with coronary heart disease: Systematic review and meta-analysis of randomized controlled trials. Amer. J. Med. 116:682-692.

Turner, L.W., M.A. Bass, L. Ting, and B. Brown. 2002. Influence of yard work and weight training on bone mineral density among older U.S. women. J. Women Aging 14:139-148.

U.S. Department of Health. 1975. Education and welfare: Blood pressure levels of persons 6-74 years. United States 1971-1974. Data from the National Health Survey, NO203 DHEW Publication (HRA) 78-1648, Vital and Health Statistics, U.S. Government Printing Office, Washington, DC.

Walsh, J.M.E., A.R. Pressman, J.A. Cauley, and W.S. Browner. 2001. Predictors of physical activity in community-dwelling elderly white women. J. Gen. Intern. Med. 16:721-727.

Wood, P.D. 1994. Physical activity, diet, and health: Independent and interactive effects. Med. Sci. Sports Exerc. 26:838-843.

Yu, Z., X. Ye, J. Wang, Q. Qi, O.H. Franco, K.L. Rennie, A. Pan, H. Li, Y. Liu, F.B. Hu, and X. Lin. 2009. Associations of physical activity with inflammatory factors, adipocytokines, and metabolic syndrome in middleaged and older chinese people. Circulation 119:2969-2977.

Zhao, W., S. Ukawa, T. Kawamura, K. Wakai, M. Ando, K. Tsushita, and A. Tamakoshi. 2015. Health benefits of daily walking on mortality among younger-elderly men with or without major critical diseases in the new integrated suburban seniority investigation project: A prospective cohort study. J. Epidemiol. 25:609-616.

Ziccardi, P., F. Nappo, G. Giugliano, K. Esposito, R. Marfella, M. Cioffi, F. D’Andrea, A.M. Molinari, and D. Giugliano. 2002. Reduction of inflammatory cytokine concentrations and improvement of endothelial functions in obese women after weight loss over one year. Circulation 105:804-809.

Zmijewski, P., K. Mazurek, E. Kozdron, P. Szczypiorski, and A. Frysztak. 2015. Effects of organized physical activity on selected health indices among women older than 55 years. ScientificWorldJournal 2015:8. 